DOI: $10.17805 /$ zpu.2017.1.12

\title{
Военно-политические аспекты субрегиональной интеграции в Европе
}

\author{
Ю. И. НАДТОЧЕЙ
}

МОСКОВСКИЙ ГОСУДАРСТВЕННЫЙ ИНСТИТУТ МЕЖДУНАРОДНЫХ ОТНОШЕНИЙ (УНИВЕРСИТЕТ)

МИНИСТЕРСТВА ИНОСТРАННЫХ ДЕЛ РОССИЙСКОЙ ФЕДЕРАЦИИ,

\section{МОСКОВСКИЙ ГУМАНИТАРНЫЙ УНИВЕРСИТЕТ}

В европейской политике $c$ каждым годом играют все более важную роль субрегиональные объединения. Они включают в себя территориально близко расположенные и тесно связанные в историческом, экономическом и культурном отношении страны Европы. Этим продиктована необходимость их более глубокого и всестороннего исследования. Одной из важных и недостаточно изученных сфер деятельности субрегиональных объединений стран зарубежной Европы является область безопасности и обороны. В исследовании описывается панорамная картина деятельности подобных объединений в условиях меняющейся геополитической ситуации в Европе, дается характеристика конкретных форм субрегионального сотрудничества в отдельных ее частях. При этом взаимодейст- 
вие государств внутри описываемых субрегиональных группировок рассматривается в более широких масштабах европейской и евроатлантической интеграции.

Выделяются новые тенденции в развитии субрегионального сотрудничества на фоне усиливающихся центробежных тенденций внутри Европейского союза. Все более отчетливые очертания обретает процесс постепенного группирования государств, ставящих целью решение общих для них проблем в области безопасности, обороны, военно-политического и военно-технического сотрудничества. Такие группировки и входящие в них страны формируют особую субрегиональную оборонную идентичность, которая развивается параллельно интеграционным процессам на уровне панъевропейских организаций. Автор отмечает, что данный процесс не приведет к вытеснению на периферию европейской системы безопасности ни ЕС, ни НАTO.

С точки зрения обеспечения интересов России в области ее безопасности представляется целесообразным учитывать фактор субрегионального военно-политического сотрудничества в Европе в процессе реализации Россией своего внешнеполитического курса на европейском направлении.

Ключевые слова: субрегиональные организации; Европейский союз; боевые группы ЕС; интеграция; оборона; безопасность; НАТО; Вишеградская группа; Бенилюкс, «Веймарский треугольник»

\section{ВВЕАЕНИЕ}

П роблема субрегионализма и субрегионализации как мирополитических ${ }^{1}$ феноменов до настоящего времени остается недостаточно разработанной и изученной. Ао недавнего прошлого даже в Европе, где интеграционные процессы развиваются уже не одно десятилетие, субрегиональные группировки оставались как бы в тени большой европейской политики. Тональность ей задавали такие крупные институциональные игроки, как Европейский союз и НАТО, претендовавшие на определяющую роль организаторов и регуляторов политико-экономической и военно-политической активности Старого Света.

Подобное положение вещей не способствовало разработке теоретических аспектов «малых форм интеграции» на уровне отдельных европейских субрегионов. Проблематика субрегионализма оказывалась на периферии внимания специалистов по регионам, концептуально не проработавших даже такое понятие, как «субрегион». Оно определяется некоторыми исследователями как «географически обусловленное субпространство, входящее в более крупный регион» (Cottey, 2009: Электронный ресурс).

В то же время определенный интерес научного сообщества к проблеме субрегионов обозначился ближе к рубежу XX-XXI вв., что было связано со стремлением ученых и экспертов обобщить и проанализировать опыт малых и средних европейских государств (в основном из числа бывших соцстран), вставших на путь создания субрегиональных группировок (Building Security ..., 1999).

Цель настоящей статьи состоит в том, чтобы проследить эволюцию субрегионального сотрудничества в Европе и, учитывая традиционно важную для стран континентальной Европы роль военной безопасности, рассмотреть оборонное измерение такого сотрудничества и его военно-политические аспекты.

\section{МЕТАМОРФОЗЫ СУБРЕГИОНААЬНОГО СОТРУАНИЧЕСТВА}

Аля западных исследователей в 1990-е годы было характерно рассматривать субрегионализм как своего рода способ достижения более отдаленной цели, которая ставилась молодыми восточноевропейскими демократиями, взявшими курс на Запад и стремившимися обрести членство как в Европейском союзе, так и в НАТО. Субрегиональные организации в данном случае служили своего рода промежуточной оста- 
новкой на пути к этой цели, так как позволяли постсоветским республикам Центральной и Восточной Европы координировать свои политические курсы и сверять стрелки часов, указывавшие на общий путь в евро-атлантическое будущее. По такому пути, в частности, стала развиваться созданная в 1991 г. Вишеградская группа2. Развивая экономическое сотрудничество, страны группы не забывали и о взаимодействии в области обороны.

Немаловажную роль объединения субрегионального уровня играли и для стран Северной Европы, также не желавших оставаться в стороне от интеграционных процессов на континенте. Более того, обладающие обширным опытом сотрудничества скандинавские государства проявляли инициативы по расширению кооперации не только между собой, но и с сопредельными «неевропейскими» (в смысле не принадлежавшими к зоне ЕС) странами. Так, программа «Северное измерение»³, а также площадки различных субрегиональных «советов» (Баренцева, Балтийского морей) стали своего рода перекидным мостом между расширяющимся Европейским союзом и Россией.

Важно отметить, что подобное вовлечение североевропейскими нейтральными государствами (Финляндией, Швецией) своих «неевропеизированных» соседей, прежде всего республик СНГ (и в первую очередь России), имело определенную геополитическую подоплеку. Следуя устоявшемуся курсу внеблоковых государств, упомянутые выше страны в то же время укрепляли взаимные военно-политические связи и контакты с НАТО. Как Хельсинки, так и Стокгольм, отдавая себе отчет в непредсказуемости ситуации в Европе после распада СССР и соцлагеря и памятуя о еще совсем недавнем феномене «финляндизации» ${ }^{4}$, стремились обезопасить себя через динамично развивавшиеся субрегиональные оборонные проекты и инициативы. Так, с участием Аании, Финляндии, Швеции и Эстонии были разработаны и реализованы планы по созданию Сотрудничества северных стран по вооружениям (NORDAC) (1994) и Северной координационной организации военных миротворческих операций (NORDCAPS) (1997) (Dahl, 2014). В свою очередь близкие к Скандинавии в географическом и геополитическом отношении страны Балтии инициировали проект Балтийского оборонного сотрудничества (BDC) (1994). Сформированные в его рамках четыре «опоры»Балтийский батальон (BALTBAT), Балтийская эскадра (BALTRON), Балтийская сеть радиолокации (BALTNET) и Балтийский оборонный колледж (BALDEFCOL) сформировали практическую сферу отношений между НАТО и прибалтийскими республиками еще до их вступления в ряды Североатлантического альянса (Sapronas, 1999).

Развивалось субрегиональное сотрудничество и на юге Европы, где группа государств Средиземноморья и Причерноморья (Албания, Болгария, Греция, Италия, Македония, Румыния, Турция) в 1999 г. создали многонациональную бригаду (SouthEastern Europe Brigade - SEEBRIG) в составе многонациональных миротворческих сил Юго-Восточной Европы. Эти проекты оказали определенный стабилизирующий эффект на развитие ситуации в юго-восточной части Европы, в том числе в ее наиболее проблемной части - на Балканах.

Не преуменьшая значение перечисленных примеров субрегионального сотрудничества, следует при этом выделить их локальность и узкую направленность, характерную для подобных объединений в конце 1990-х годов. Это обстоятельство подпитывало расхожую в политической и экспертной среде европейских стран точку зрения, согласно которой субрегиональные тенденции не рассматривались как долговременный 
процесс и должны были вскоре уступить место панъевропейскому сотрудничеству стран в рамках Европейского союза и Североатлантического альянса (Bailes, 1997). Подобное мнение во многом основывалось на том простом объяснении, что как ЕС, так и НАТО почти синхронно начали процесс расширения, включив в свои ряды большинство стран бывшего соцлагеря, которые, таким образом, достигли ранее обозначенной задачи по интеграции в сообщество западных стран.

Однако сам факт получения долгожданного членства в ЕС и НАТО не снял с повестки дня вопрос о целесообразности субрегионального сотрудничества ни для центральноевропейских, ни для североевропейских стран. Финляндия и Швеция к тому же сохранили нейтральный статус, вступив только в ЕС, и потому испытывали потребность в углублении военно-политической и оборонной кооперации вне рамок НАТО.

Немаловажной проблемой для новоявленных членов большой европейской семьи стала проблема сотрудничества по вопросам военной безопасности с теми странамисоседями, которые по многим причинам оказались за бортом европейской и евро-атлантической интеграции. В подобной обстановке субрегиональные организации стали выполнять еще одну важную роль объединяющего звена между внеблоковыми странами и членами НАТО. Подобную функцию, например, осуществляли североевропейские программы NORDAC ${ }^{5}$ NORDCAPS $^{6}$ и NORDSUP7 (Аания, Финляндия, Норвегия, Швеция), а также южноевропейская инициатива BLACKSEAFOR ${ }^{8}$, ставшие примером секторального взаимодействия между членами НАТО и внеблоковыми странами (New Regionalism ..., 2013).

Новым явлением европейской реальности стало укрепление и развитие трансрегиональных связей между различными субрегиональными организациями и многосторонними инициативами, в которых состав участников и их цели во многом были идентичны. К таковым, в частности, можно отнести Центральноевропейское оборонное сотрудничество (CEDC) с участием Австрии, Словении, Хорватии, Венгрии, Словакии, Чехии и Польши. Эта многосторонняя инициатива объединила как страны Вишеградской группы, так и их соседей, желающих большего углубления оборонного сотрудничества на субрегиональном уровне (Central European ... , 2014: Электронный ресурс).

\section{СУБРЕГИОНАИЬНОЕ СОТРУАНИЧЕСТВО И КРИЗИС ЕС}

Свой отпечаток на процессы субрегионального сотрудничества наложила и общая ситуация в Европейском союзе, который к середине 2010 г. не только растерял ранее присущий ему энтузиазм к расширению, но и начал испытывать серьезные процессы внутренней эрозии. Размывание целостности и субъектности ЕС понизило и его позитивный потенциал международного влияния, в том числе на сопредельные страны и регионы.

В отличие от 1990-х и начала 2000-х годов, когда активная политика ЕС способствовала урегулирование конфликтов на европейской периферии (Балканы) или даже на других континентах (Африка), новые проекты сотрудничества ЕС с соседями оказались гораздо менее продуктивными. В ряде случае они становились не только спорными с точки зрения обеспечения безопасности Союза, но и наносили ему прямой или косвенный вред. Так, неудачная политика ЕС в отношении стран Северной Африки и Ближнего Востока (Союз для Средиземноморья) и не менее нерезультативная программа Восточного партнерства привели к возникновению вокруг ЕС своего рода пояса нестабильности, простирающегося от Балтики до Средиземного моря. 
Что еще более важно, недостаточно эффективными оказались и внешнеполитические и оборонные механизмы ЕС - общая внешняя политика и политика безопасности (ОВПБ), а также ее логическое продолжение - общая политика безопасности и обороны (ОВПБ).

В условиях повышенной международной напряженности, помноженной на внутренние экономические неурядицы, странам - членам ЕС и НАТО стало все сложнее достигать консенсуса при выработке единой стратегической динии в области безопасности и обороны.

На таком фоне субрегиональные группы начинают обретать новый смысл существования и все чаще воспринимаются элитами и общественностью отдельных европейских стран не просто как придаток ЕС или НАТО, но как альтернативный путь развития европейской интеграции. Менее благоприятная обстановка в мире и в самой Европе предопределяет и выделяет в деятельности локальных групп стран новое военно-политическое и оборонное измерение.

Все более отчетливым становится запрос на более гибкие схемы многостороннего сотрудничества в области «жесткой» (военной) или «мягкой» (невоенной) безопасности. Они существенно увеличивают возможности кооперирующихся стран, испытывающих недостаток сотрудничества в рамках классических военно-политических союзов. Можно отметить, что Североатлантический альянс, еще в недавнем прошлом претендовавший на центральную роль в вопросах обеспечения европейской безопасности, также переживает кризис внутреннего единства, поскольку в настоящее время объединяет 28 стран с зачастую весьма разными военно-стратегическими целями и, что самое главное, потенциалами для их достижения.

Гуманитарный кризис, связанный с наплывом в Европу беженцев с Ближнего Востока, а также участившиеся теракты в отдельных европейских государствах продемонстрировали своего рода дефицит воли у ЕС и НАТО, которая была столь необходима этим организациям Аля эффективного реагирования на кризисы. В то же время скоординированные усилия отдельных стран в рамках субрегиональных организаций позволили в немалой степени упростить противодействие упомянутым вызовам и угрозам.

В условиях отсутствия прежде единой угрозы, ранее объединявшей евро-атлантическое сообщество, система взаимных обязательств НАТО в области коллективной обороны все чаще подвергается критике ведущими членами альянса. Политическое и военное руководство ведущей силы блока - Соединенных Штатов подталкивает европейских союзников к большей самостоятельности. Однако их зависимость от Вашингтона в военной области сказывается на качестве межсоюзнического взаимодействия. НАТО в таких условиях все сложнее решать вопрос справедливого распределения бремени членства для всех входящих в блок государств.

\section{ГРУППЫ «ПО ИНТЕРЕСАМ»}

Субрегиональные же объединения и группы в этом смысле обладают бо́льшим преимуществом, так как их участники менее связаны формальными обязательствами, блоковой дисциплиной и бюрократическими процедурами. Сотрудничество между соседствующими странами, обладающими сходной «культурой безопасности», позволяет достичь большей гармонизации и синхронизации оборонных политик и стратегий. В этом смысле субрегиональная кооперация в большей степени ориентирована на результат, реализуясь на секторальном взаимодействии «по интересам». Она 
лишена многих недостатков «больших» региональных и международных структур, которые малоадаптивны к быстро меняющимся условиям.

Крайне перспективной для развития отношений между тесно связанными в экономическом и историческом планах сопредельными странами оказалась сфера военнотехнического взаимодействия. Углубляя сотрудничество, они переводили его в новые плоскости, включая столь чувствительную с политической точки зрения область, как «жесткая» безопасность. Подобных примеров для взаимодействия выявилось достаточно много - от транспортно-логистического сотрудничества и совместных закупок военной техники до создаваемых на многонациональной основе боевых формирований.

Существенные достижения на оборонном направлении сотрудничества достигли как старейшие субрегиональные группировки Западной Европы (Бенилюкс), так и относительно молодые объединения центральноевропейского субрегиона (Вишеградская группа). Участники этих объединений, в частности Бельгия, Нидерланды и Аюксембург, использовали своего рода «открытый интеграционный код», позволивший присоединяться к их оборонным проектам и программам другим странам-партнерам и организациям, заинтересованным в таком сотрудничестве. В частности, созданная по решению «тройки» мобильная тактическая авиагруппа Deployable Air Task Force стала одним из первых удачных примеров по совместной закупке и эксплуатации боевых самолетов F-16 и в какой-то мере способствовала разработке концепции совместного разделения и использования потенциалов pooling and sharing уже на уровне EC (Orr, 2003: Электронный ресурс).

Не менее успешными в вопросах оборонного взаимодействия оказались и страны Северной Европы, выделившие пять областей совместной деятельности в рамках Северного оборонного сотрудничества (Nordic Defence Cooperation - NORDEFCO) ${ }^{9}$. В числе этих областей значатся стратегическое развитие, потенциал, кадры и образование, подготовка и учения, а также операции (Dahl, 2014). Как и в случае со странами Бенилюкса, наиболее важные области взаимодействия NORDEFCO сконцентрированы вокруг авиации, с тем отличием, что скандинавские страны выделили в качестве приоритета развитие транспортных перевозок, создав Северное тактическое авиатранспортное крыло (Nordic Air Transport Wing) (Signed agreement on Air ... , 2013: Электронный ресурс).

Невозможно оставить незамеченными и такие многосторонние инициативы, как Гентский процесс ${ }^{10}$ или оборонное сотрудничество в рамках «Веймарского треугольника»11 (Dickow et al., 2011: Электронный ресурс). Эти форматы взаимодействия между отдельными европейскими странами хотя и являются скорее трансрегиональными с географической точки зрения, так как включают в себя государства из разных частей Европы, однако имеют определенное ядро из двух-трех государств-соседей. И именно они выполняют в таких инициативах ведущую роль.

\section{СУВЕРЕНИТЕТ ВМЕСТО НААНАЦИОНААЬНОСТИ}

Опасений насчет возможности ограничения национального суверенитета у участников субрегиональных объединений, как правило, не возникает, поскольку таковые, в отличие от того же ЕС, организованы не на принципах наднациональности и субсидиарности, а на основе сотрудничества между суверенными государствами. Оборонная сфера, таким образом, остается в руках национальных правительств в полном объеме, специализация и кооперация осуществляются на проектной «деполитизиро- 
ванной» основе, реализуются по конкретным техническим направлениям, и суверенитет стран-участниц никак не ограничивается. Субрегиональные группы хотя и прибегают к риторике о необходимости создания «общих армий», на деле ограничиваются более скромными, хотя и многообещающими инициативами (Visegrad Countries ... , 2016: Электронный ресурс). Например, страны Вишеградской группы уже объявили о намерении вывести совместно создаваемую боевую группу за рамки ЕС, наделив ее статусом автономного формирования - «постоянных сил реагирования $\mathrm{V} 4$ » $(\mathrm{Bu}-$ dapest Declaration ... , 2015: Электронный ресурс).

Ни ЕС, ни НАТО не в состоянии подменить собой подобные сообщества или интегрировать их в себя. А учитывая успехи таких сообществ и групп, отношение к ним со стороны ведущих европейских организаций даже меняется в лучшую сторону. Некоторый скепсис со стороны ЕС и НАТО к подобным «малым» сообществам хотя и не исчез полностью, но не может препятствовать признанию значимости субрегионализма. Это явление и процесс не могут не учитываться Брюсселем и при разработке общего интеграционного курса в отношении входящих в локальные сообщества отдельных стран - членов ЕС и НАТО.

В конечном счете оборонные инициативы, реализуемые на субрегиональном уровне, позволяют эффективно решать застарелую проблему оптимизации военных расходов. А при достаточной степени взаимодействия между субрегиональными группировками и панъевропейскими организациями первые вполне способны аккумулировать такой силовой потенциал, который может быть использован уже на уровне ЕС и НАТО.

В какой мере субрегиональные организации окажутся способными стать подрядчиками как НАТО, так и ЕС в вопросах обеспечения европейской безопасности, покажет будущее. На сегодняшний же день такая готовность с их стороны пока не наблюдается, что показывает упомянутый пример боевых групп ЕС.

\section{ЗАКАЮЧЕНИЕ}

Формирование субрегиональных сообществ и инициатив в современной Европе стало неотъемлемой частью политического ландшафта континента. Однако выделение в деятельности подобных локальных групп нового направления - военно-политического, а следовательно, и перевод субрегиональных процессов в плоскость «жесткой» безопасности символизируют собой важную отправную точку развития тенденций в области интеграции и, что более важно, ограниченной дезинтеграции политического пространства Европейского союза.

Обозначившийся к середине второго десятилетия XXI в. новый феномен - «сужение» ЕС из-за вероятного выхода некоторых отдельных стран Союза - актуализировал значимость субрегиональных объединений. Создающие их страны-соседи все чаще начинают воспринимать такие группировки если и не в качестве полной альтернативы организациям панъевропейского уровня, то по меньшей мере как важные вспомогательные механизмы, восполняющие пробелы европейской и евро-атлантической интеграции.

Российской Федерации, традиционно уделяющей много внимания взаимодействию с ведущими организациями - игроками европейской авансцены, прежде всего ЕС и НАТО, важно не оставлять на периферии своей международной повестки дня фактор субрегиональных группировок. С учетом возрастания роли последних в процессах, непосредственно влияющих на состояние дел в области безопасности и обо- 
роны в Европе, для России крайне важно наладить контакты «альтернативной коммуникации» с входящими в такие сообщества странами-участницами, расширив тем самым свои политико-дипломатические возможности и создав дополнительные гарантии своей безопасности.

\section{ПРИМЕЧАНИЯ}

1 Мирополитический подход в политической науке исходит из того, что глобальные процессы влияют и преломляются, в том числе, на региональном и субрегиональном уровнях.

2 Вишеградская группа - неформальное объединение четырех государств Центральной и Восточной Европы (Польши, Чехии, Венгрии и Словакии), созданное в целях углубления и расширения сотрудничества между ними в области экономики, политики и безопасности.

${ }^{3}$ Северное измерение - совместная политика североевропейских стран - членов ЕС (Финляндии, Швеции), Российской Федерации, Норвегии и Исландии, а также стран Балтии. Политика является основой для развития диалога, укрепления стабильности, благополучия и экономического сотрудничества, продвижения экономической интеграции, конкуренции и устойчивого развития в Северной Европе.

4 Понятие было введено в политологический оборот после Второй мировой войны в связи с установившимся особым характером советско-финских отношений. В частности «финляндизация» подразумевала возможность получения Финляндией определенных экономических и политических преимуществ от отношений с СССР взамен на отказ от вступления в военные союзы Запада.

5 Северное сотрудничество по вооружениям (Nordic Armaments Cooperation) - программа сотрудничества между Аанией, Норвегией, Швецией и Финляндией в сфере совместных разработок, закупок и обслуживания военной техники и оборудования.

6 Сотрудничество Северных стран в организации военных миротворческих операций (Nordic Coordinated Arrangement for Military Peace Support) - программа сотрудничества между Аанией, Норвегией, Швецией и Финляндией в области миротворчества с использованием военной силы.

7 Развитие северных вспомогательных оборонных структур (Nordic Supportive Defence Structures) - программа развития управленческих структур по реализации NORDAC и NORDCAPS.

8 Черноморская военно-морская группа оперативного взаимодействия. Участниками группы являются государства Причерноморья - Болгария, Румыния, Россия, Турция, Украина и Грузия.

9 Оборонное сотрудничество Северных стран - программа сотрудничества между Исландией, Аанией, Норвегией, Швецией и Финляндией, созданная с целью уменьшения расходов на оборону и повышения эффективности армии, флота и авиации странами - участницами программы.

10 Гентский процесс, или «Гентская инициатива» - пакет мер, озвученных министрами обороны стран - членов ЕС в декабре 2010 г. в г. Генте (Бельгия). Набор рекомендаций был нацелен на укрепление оборонных возможностей Европейского союза.

11 Неформальный совещательный форум с участием Польши, Германии и Франции, созданный в 1991 г. с целью развития партнерских отношений между странами-участницами.

\section{СПИСОК АИТЕРАТУРЫ / REFERENCES}

Bailes A. (1997) Sub-regional organizations: The Cinderellas of European security // NATO Review. № 2. P. 27-31.

Building Security in Europe's New Borderlands: Subregional Cooperation in the Wider Europe (1999) / ed. by R. Dwan. N. Y. : EastWestInstitute.

Budapest Declaration of the Visegrad Group Heads of Government on the New Opening in V4 Defence Cooperation (2014) [Электронный ресурс] // Visegrad Group Official Website 
URL: http://www.visegradgroup.eu/calendar/2014/budapest-declaration-of (дата обращения: 29.10.2016).

Central European Defence Cooperation SOF Conference opens in Split (2014) [Электронный реcypc] // Ministry of Defence of the Republic Croatia. URL: https://www.morh.hr/en/news/pressreleases/9498-central-european-defence-cooperation-sof-conference-opens-in-split14042014.html (дата обращения: 23.09.16).

Cottey, A. (2009) Sub-regional Cooperation in Europe: An Assessment [Электронный ресурс]// Bruges Regional Integration \& Global Governance Papers. № 3. URL: http://aei.pitt.edu/33535/1/ BRIGG_3-2009_Cottey.pdf (дата обращения: 12.10.15).

Dahi, A. (2014) NORDEFCO and NATO: "Smart defence" in the North// NATO Research Paper. № 101. P. 1-12.

Dickow, M., Linnenkamp, H., Maulny, J., Terlikowski, M. (2011) Weimar Defence Cooperation Projects to Respond to the European Imperative. Report of the Polish Institute of International Affairs. Warsaw [Электронный ресурс] // Polish Institute of International Affairs. URL: http:// www.pism.pl/files/?id_plik=10417 (дата обращения: 22.11.15).

Signed Agreement on Air Transport Assets (2013) [Электронный ресурс]// Norway Government Website. URL: https://www.regjeringen.no/en/aktuelt/signed-agreement-on-air-transport-assets/ id747330/ (дата обращения: 28.10.16).

Orr, D. (2003) The Benelux Deployable Air Task Force: A Model for EU/NATO Defense Force Integration // Air \& Space Power Journal. Vol. 17. №3. URL: http://www.au.af.mil/au/cadre/ aspj/airchronicles/apj/apj03/fa103/orr.html (дата обращения: 17.09.16).

New Regionalism or No Regionalism? Emerging Regionalism in the Black Sea Area (2013), ed. I. Ruxandra. Burlington : Routledge. 256 p.

Sapronas, R. (1999) BALTBAT and development of Baltic Defence Forces // Baltic Defence Review. № 2. P. 55-70.

Visegrad Countries Urge EU to Build a Common Army (2016) [Электронный ресурс] // Deutsche Welle. 26.08. URL: http://www.dw.com/en/visegrad-countries-urge-eu-to-build-a-common-army/a-19507603 (дата обращения: 17.09.16).

Аата поступления: 23.10.2016

\section{POLITICAL ANDMILITARY DIMENSION OF SUBREGIONAL INTEGRATION IN EUROPE \\ Y. I. NADTOCHEY \\ MOSCOW StATE INSTITUTE OF INTERNATIONAL RELATIONS (MGIMO UNIVERSITY), MOSCOW UNIVERSITY FOR THE HUMANITIES}

European subregional groupings embracing neighboring countries which are deeply interdependent in terms of history, politics and security, are playing an increasingly important role in European affairs. The study of different aspects of aforementioned groupings and organizations seems to be an imperative for political scholars and analysts.

One of the key dimensions of subregional groupings' activity which is not deeply covered by Russian political science and region studies is the area of security and defense.

Taking into account the changing geopolitical environment in modern Europe, the current study provides a panoramic view of this area and gives a description of particular subregional cooperation formats. Moreover, the study does not focus purely on internal cooperation among countries within the subregional groupings, but also explains how this cooperation is being influenced by the European and Euro-Atlantic integration. New tendencies of subregional cooperation are being outlined against the increasing background centrifugal trends in the European Union.

By aligning in narrow groups, neighboring countries seek for joint solutions in the area of security, defense and political and military relations in general.

These groups form a kind of specific subregional security and defense identity which is developing in parallel with the integration on EU and NATO level. Although this kind of identity might hardly be estimated as threatening to both EU and NATO, it must be carefully analyzed, nevertheless. 
For security reasons Russia has to take into account European subregional groupings while implementing its policy towards Europe.

Keywords: subregional groupings and organizations; defense and security; NATO; European Union; CFSP; CSD; EU battle groups; Visegrad Group; Benelux; Weimar Triangle

Submission date: 23.10.2016.

Надточей Юрий Иванович - кандидат исторических наук, доцент кафедры мировых политических процессов Московского государственного института международных отношений (Университета) Министерства иностранных дел Российской Федерации, доцент кафедры международных отношений и дипломатии Московского гуманитарного университета. Адрес: 111395, Россия, г. Москва, пр. Вернадского, д. 76. Тел: +7 (495) 434-94-14. Эл. адрес: ynadtochey@yandex.ru

Nadtochey Yury Ivanovich, Candidate of History, Associate Professor at the Department of World Political Trends, Moscow State Institute of International Relations (MGIMO University), Associate Professor at the Department of International Relations and Diplomacy, Moscow University for the $\mathrm{Hu}-$ manities. Postal address: 76 Prospect Vernadskogo, Moscow, Russia, 119454. Tel.: +7 (495) 434-94-14. E-mail: ynadtochey@yandex.ru 